\title{
Roles of Counsellors in Promoting Sexuality Education for In-School Adolescents in Nigeria
}

\author{
Joachim C. Omeje, Eskay Michael \\ University of Nigeria, \\ Nsukka, Nigeria
}

\author{
Modebelu Josephine Obiageli \\ St. Augustine College of Education, \\ Yaba Lagos, Nigeria
}

\begin{abstract}
Research was embarked upon to investigate the role of counselors in promoting sexuality education for in-school adolescents in Nigeria. The respondents were made up of 120 practicing guidance counselors in Enugu State situated in South-East geopolitical zone of Nigeria. They were drawn from both professional and teacher counselors practicing in 220 public secondary schools in the state. Structured questionnaire and respondent's perceptions were data gathering instrument. The findings show that their identified roles are value re-orientation for students, enlightenment programme for parents on the need for the growing adolescents to be kept abreast of their developmental changes, information dissemination on benefits inherent in sexuality education, and creating awareness through lectures, seminars, workshops, and conferences on the objectives of sexuality education. However, they are constrained in carrying out these roles because of lack of fund, lack of awareness on what sexuality education is all about cultural and religious interferences. It equally perceived that measures like provision of adequate funds, removal of cultural inhibition, the use of media and moral instruction, as well as value re-orientation could be used to eliminate the constraining factors. Based on the above, policy-makers were called upon to find intervention strategies for removal of the constraints as a way for enhancing sexuality education at secondary schools.
\end{abstract}

Keywords: counseling, special education, advocacy, litigation, sex education

\section{Introduction}

Adolescence stage marks the heightened emotional state in the life of individuals. Teenagers at this stage reach the climax of their instability and at the same time lay the foundation of their future life (Grugni, 1996). They are usually taken by surprise by the development and problems, which confront them when they arrive at this period of life. They do not know who to approach for guidance and in their anxiety usually seek help from wrong sources. This may account for a good percentage of teenage pregnancy, sexual permissiveness and abuse, and other immoral behaviours ravaging our youths these days.

In the past, it was assumed in Nigeria traditional setting that the best way of preventing sexual immorality among the youths was to keep them in complete ignorance of sex matters. Children were brought up to uphold chastity and obey their parents' instructions without questioning. The young growing adolescence was kept in total blackout.

Joachim C. Omeje, Ph.D., Department of Educational Foundations, University of Nigeria.

Eskay Michael, Ph.D., professor, Department of Educational Foundations, University of Nigeria.

Modebelu Josephine Obiageli, St. Augustine College of Education. 
The above may have informed the decision of the federal government of Nigeria to introduce sexuality education in our schools where the students will be taught proper sex knowledge. But the strong raging debate about this decision especially from religious angles is its serious and deep negative impact on the psyche and public behaviour of the young ones. This negative imparts range from loss of moral values, religious principles and law to social and emotional mismanagement. The above may have affected the promotion of sexuality education in secondary schools and in light of the above, the researcher will want to explore the role of counselors in promoting sexuality education in secondary schools in Nigeria.

The notion of human sexuality and/or sexology is intermingled with simple but complex interpretations of very common and attractive words like love, sex, affection, and friendship. Depending on the situation, each terminology generally conjures elements of negative, positive, or mixed feelings of emotions that can set the heart throbbing within the individual irrespective of gender, position, race, creed, or colour (Ochiagha, 1999). People are now thrown into confusion because of the presence of STDs (sexually transmitted disease), HIV (human immunodeficiency virus)-infection and AIDS (acquired immuned deficiency syndrome), sex abuse, prostitution, and rape among others. These call for urgent need for sexuality education in schools even though there are negative reactions toward its introduction.

Sexuality education is seen as transmission of appropriate sex based knowledge, values, attitudes, and roles to children. It seeks to teach boys and girls the physiological functioning and use of sex organs and the expected roles of each sex. This means that biological facts about sex are only a part and not the whole of sex education. For Ochiagha (1997), human sexuality education is a programmed-package for equipping individuals with appropriate knowledge, information, and skills that would enable them to understand and handle their sexuality personally and in relation to others. This is an effort to create awareness in males and females of the need to learn to take appropriate decision and responsibilities in whatever stage of development regarding of friendship, sex, mate-selection, and other marriage issues in accordance with positive socio-cultural, moral, economic, spiritual, educational/vocational expectations and aspirations.

Although sexuality education preaches free socialization of children with age-mates, experiences have shown that these inherent positive aspects of the education are not manifesting in the lives of the young peoples. The experience of free association of age-mates no-matter the sex, which sexuality in school education advocates appears more dangerous to the young one as regards the sexual morality than promoting sexual maturity. It is therefore important to examine the roles of counselors in promoting sexuality education for in school adolescents.

The study of sexuality education hinges on the theory of reasoned action model, the health action process model, and the health belief model. These theories focus upon the importance of socio-cognitive variables in preventive health. Some of these models emphasize the importance of volitional decision of individuals about the perceived utility of their actions. This emphasis on individual volitional decision is central to the health belief models upon which the present study is anchored. As noted by Manderson (1998), the health belief model, which is a major conceptual framework of health education and promotion, hinges on the direct relationship between knowledge and behaviour. Sexuality education can be imparted through health education programme. A lot has been discussed in relation to sexuality education: importance of it and the role of media in sexuality education, but no known research has focused on the role of counselors. It is against this background that this study sought to assess the role of counselors in promoting sexuality education. This study also examined counsellors' knowledge of their roles in promoting sexuality education. It equally sought to find 
out the constraining factors in the discharge of these roles. Finally, the study sought out measures to be adopted in eliminating the constraining factors.

Human sexuality is seen as a sacred issue that raises much doubt about the morality of anyone who ventures to discuss it. As a result of this, the adolescents were left to mature to adulthood with whatever knowledge they could gather about sex from peer groups in the course of their development. The effect is always devastating. In spite of the present technological breakthrough, Nigerian cultural values and attitudes remain static, which has affected the stand of significant others in the life of the adolescents in terms of letting them know. Parents, elders, the elites, and even schools have refused to let the adolescents know their body mechanism and functions. There is the superstitious belief that giving them sexuality education will help to increase sexual promiscuity. These are mere belief and should be discarded. Nwabuisi (2000) opined that traditional values are very important and rewarding but when they have negative influence on the development to the extent that they become a barrier to national interest and unity, attachment to them should be re-examined, discouraged, or modified.

The above notion reflects the need for the integration of counseling in sexuality education. Counseling has been used to denote a wide range of procedures including advice-giving and support in times of trouble or need, encouragement, information-giving and test interpretation. The Federal Republic of Nigeria in 1998 acknowledged guidance and counseling as an essential educational service that facilitates not only the implementation of educational policy, but also the attainment of the policy goals at all levels of education (Harold, 2002), and the promotion of the effectiveness of the educational system. The overall aim of guidance and counseling is the enhancement of academic, vocational, and personal/social development as well as emotional, social, and life planning effectiveness in individuals (Araniego, 2003). Guidance and counseling as opined by Omeje (2003) is an inter-personal relationship in which the counsellor helps the client who is in need to fully understand self and properly adjust within the environment he/she finds himself/herself. That is making the client to be able to resolve conflict in life. Conflict as referred here implies any block that an individual is confronted in the course of development of which sexuality is part. On the use of workshop, seminars/conferences to highlight sexuality education issues, Okumu (2001) said that a well-planned human sexuality programme can be set up as a guide to provide a step-by-step information service through the use of seminars/conferences as well as workshops.

There is an urgent need to address the issue of sexuality education being implemented within the school system. This is because if the issue is left unattended our adolescent will be left in confused state in which they will resort to any available means to solve their problems. When such adolescents learn that the values and attitudes they had unquestionably accepted were not necessarily shared by neighbours, peers, and co-workers as a result of increased mobility and social mixing, life becomes more complex and permissive.

\section{Methods}

The study area was Enugu State situated in South-East geopolitical zone of Nigeria. It has six education zones: Viz Agbani, Awgu, Enugu North, Obollo-Afor, Nsukka, and Udi education zones with 220 public secondary schools.

The total population of practicing counselors in the secondary schools was 240 . This included both professional counselors and teacher-counselors. The teacher-counsellors are stopgap counselors, who are used where there is no professional counsellor. The sample of 120 practicing counselors was selected randomly from 
the population. A list of the names of the counsellors was brought and numbered 1-240. The numbers were folded, mixed up, and placed in a bag. A neutral person was made to pick $50 \%$ of the population from the bag, which came to 120 samples used for the study.

The draft questionnaire with a 4-point response pattern of SA ("Strongly agreed"), A ("Agreed"), D ("Disagreed"), and SD ("Strongly disagreed"), with assigned weight of 4, 3, 2, and 1 points respectively developed by the researcher was trail tested by administering it to practicing counselors in private owned schools. Based on experiences encountered during the trail testing of the questionnaire, modifications were made. Also, the internal consistency of the reliability was ascertained through Cronbach alpha and a reliability coefficient of 0.78 was reached.

The data collected from the study were analyzed using frequency, percentage, and mean score. A mean score of 2.50, which is the average of the weighted responses, was used as our criterion point. As the items of the questionnaire were positively framed, any score from 2.50 to 4.0 was an indication of agreement with the item of the questionnaire while below 2.50 was an indication of disagreement.

\section{Results}

The percentage of the professional counsellor respondents was $78 \%$ while the teacher-counsellor respondents accounted for $22 \%$ (see Table 1). Male respondents accounted for $29 \%$ while female respondents accounted for $71 \%$ (see Table 2). On working experience eight respondents (7\%) indicated having worked below five years, 60 respondents representing 50\% indicated at 5-10 years, 40 respondents (33\%) indicated 11-15 years, while 12 respondents (10\%) indicated having worked above 15 years (see Table 3 ).

Table 1

Status of the Counsellors $(n=120)$

\begin{tabular}{lcc}
\hline Status & $n$ & Percentage (\%) \\
\hline Professional counsellors & 93 & 78 \\
Teacher-counsellors & 27 & 22 \\
Total & 120 & 100 \\
\hline
\end{tabular}

Table 2

Demographic Variable of Professional Counsellors $(n=120)$

\begin{tabular}{lcc}
\hline Gender & $n$ & Percentage $(\%)$ \\
\hline Male & 35 & 29 \\
Female & 85 & 71 \\
Total & 120 & 100 \\
\hline
\end{tabular}

Table 3

Years of Counselling Experience $(n=120)$

\begin{tabular}{lcc}
\hline Year of experience & $n$ & Percentage $(\%)$ \\
\hline$<15$ & 8 & 7 \\
$5-10$ & 60 & 50 \\
$11-15$ & 40 & 33 \\
$>15$ & 12 & 10 \\
Total & 120 & 100 \\
\hline
\end{tabular}

In determining roles, counselors can play in promoting sexuality education, the respondents strongly 
agreed with the roles identified in the questionnaire. This was based on attainment of mean scores $3.74,3.42$, 3.85 , and 3.71 points respectively for the four items of the questionnaire.

Table 4

Counsellors' Roles in Promoting Sexuality Education

\begin{tabular}{|c|c|c|c|c|c|c|}
\hline \multirow{2}{*}{ Item description } & \multicolumn{6}{|c|}{ Frequency } \\
\hline & $\mathrm{SA}$ & A & $\mathrm{D}$ & $\mathrm{SD}$ & $\sum \mathrm{F}$ & $\overline{\mathrm{X}}$ \\
\hline Value re-orientation for students & 94 & 21 & 5 & - & 445 & 3.74 \\
\hline $\begin{array}{l}\text { Enlightenment programme for parents on the need for the growing } \\
\text { adolescents to be kept abreast of their developmental changes }\end{array}$ & 80 & 15 & 20 & 5 & 410 & 3.42 \\
\hline Information dissemination on benefit inherent in sexuality education & 102 & 18 & - & - & 462 & 3.85 \\
\hline $\begin{array}{l}\text { Creating awareness through lectures, seminars, workshops, and } \\
\text { conferences on the objectives of sexuality education }\end{array}$ & 98 & 12 & 7 & 3 & 445 & 3.71 \\
\hline
\end{tabular}

The analysis of the data collected as indicated in Table 4 shows that the respondents rated all the four items identified as roles of the counselors in promoting sexuality education very high, which is an indication for their agreement with the items. The item on information dissemination on benefits inherent in sexuality education was the highest rated with a mean score of 3.85. The least related on the table was carrying out enlightenment programme for parents on the need for the growing adolescents to be kept abreast of their developmental changes with a mean score of 3.42 .

There was the need to ascertain from the respondents if there were constraining factors in the discharge of these roles (see Table 5). They were asked to indicate based on their perceptions of the identified roles what they feel may be some of the constraining factors.

Table 5

Constraining Factors $(n=120)$

\begin{tabular}{lcc}
\hline Constraining factor & $n$ & Percentage (\%) \\
\hline Lack of fund & 120 & 100 \\
Lack of awareness on the side of the public on what sexuality education is all about & 90 & 75 \\
Cultural interference & 96 & 80 \\
Religious interference & 96 & 80 \\
\hline
\end{tabular}

There is virtually high perception on lack of fund as a constraining factor to sexuality education. This was irrespective of counsellor's status. The respondents know that fund is a crucial factor in sexuality education based on the mode of imparting the information. There was also $75 \%$, which accounted for 90 respondents who felt that lack of awareness on the side of public of which the recipients and their guardians were part is a constraining factor. Cultural interference and religion were equally identified as constrains. Ninety-six respondents $(80 \%)$ felt that culture and religion constitute obstacles to sexuality education. This may not be far from the fact that talking about sexuality education in our society seems to most people that a selected few are making efforts to break down the basic structures of human society to over throw traditional moralities and wipe out all forms of religion and belief in our absolute God. Many parents believe that innocence can be preserved through ignorance. This is not as parents must do their best to reduce, and if possible, stop all the adolescence delinquencies that are at work these days in our society. Finally, the respondents were asked to indicate in their own opinion measures that could be used in promoting sexuality education in secondary schools. The analysis of data collected indicates provision of funds, removal of cultural inhibitions, the use of 
media, moral instructions where religious bodies will be utilized, and value re-orientation as measures that can be used in eliminating the constraining factors.

Table 6

Measures for Eliminating the Constraining Factors $(n=120)$

\begin{tabular}{lll}
\hline Measure & $n$ & Percentage (\%) \\
\hline Provision of adequate funds & 120 & 100 \\
The use of media & 120 & 100 \\
Value re-orientation & 120 & 100 \\
The use of moral instructions & 96 & 80 \\
Removal of cultural inhibitions & 90 & 75 \\
\hline
\end{tabular}

The views of the respondents as indicated in Table 6 on measures to be used in eliminating the constraining factors to sexuality education show that providing adequate funds, the use of media as well as value re-orientation were virtually accepted as measures. The three variables had $100 \%$ responses respectively. This may not be far from the fact that in achieving any worthwhile objective, fund is of paramount importance. On the side of the mass media, its influence on the general public is enormous. One of the aims of mass media is to make the individuals and groups aware of the value, norms, and acceptable pattern of behaviours in the society which sexuality education sets out to achieve.

\section{Discussion}

The finding that counselors' role in promoting sexuality education include value re-orientation for students, enlightenment programme for parents on the need for the growing adolescents to be kept abreast in their developmental changes, information dissemination on benefits inherent in sexuality education, and creating awareness through lectures, seminars, workshops, and conferences on the objective of sexuality education is in line with the view of Ochiagha (1999). The author opined that counsellor in promoting sexuality education should find a way of dealing with the public who are tied up with cultures. The counsellor can do by explaining to them what sexuality education entails as well as making them to have a positive value attachment to issue of sex. Bulus (1990) said that counselling service is intended for all people: young, old, rich, poor, rulers, and subjects, not only when in trouble, but also to plan their lives and that of their society meaningfully. It is given professional advice and guidance through information, dissemination, and enlightenment programme for parents to change their perception as well as value re-orientation for the youths. These roles are needed urgently in the society today where sexual permissiveness is trying to create a lot of problems to adolescents.

However, the implications of using counseling as a means of implementing sexuality education in secondary schools are enormous, so we should realize the fact that the counsellor is dealing with a society that is yet to fully appreciate the need for guidance and counseling, and people tied up with cultures. Based on the above, the counsellor should direct his/her counselling towards changing the public's value attachment, enlightening parents on the need for their children to be informed on benefit associated with sexuality education. These can be done through lectures, seminars, workshops, and conferences.

The study equally revealed some factors constraining them in exercising the outlined roles. Such factors are lack of fund and lack of awareness on the side of the public on what sexuality education is all about cultural and religious interferences. The finding is in line with Grugni (1996), who held that the issue of sexuality education is a sorry situation. Identifying the reason behind the sorry situation, he opined that difficulties in 
implementing sexuality education have their roots in the refusal to accept sexuality as a rich and positive value for the full expression of human personality. It amounts to relegating sexuality to a mere means for procreation or otherwise a source of dangerous tendencies and sins. Many people and cultures have continued to hold human sexual emotions so sacred that open discussion about it attracts a kind of shyness, unfriendliness, and repulsion. Sexuality was looked upon as mysterious and sacred and this affected the implementation of sexuality education in schools.

Some parents find it difficult to discuss issues of sexuality with the young growing ones on the ground that culture and religion forbid opine discussion on sexual issues. Most religious groups are nervous about sex education. The church especially the Catholic in Nigeria is sensitive to the issue of sexuality. At the Catholic Bishops conference on September 12-16, 2005, sex education was one of the issues discussed. They expressed concern about the move by federal government of Nigeria to introduce a curriculum for sexuality education at the junior and senior secondary school levels, which according to them, is harmful to the ethical development of the young because to them the curriculum does not take into consideration the level of human development and maturity of the young ones, nor the African culture and tradition. The above corroborates the finding that cultural and religious interferences are constraining factors to counselors' exercising of the identified roles in promoting sexuality education.

Equally, the study reveals that such identified constraining factors can be eliminated through adequate funding, the use of media, value re-orientation, the use of moral instructions, and removal of cultural inhibitions. The finding is in line with Okunwa (1999) who opined that the mass media provide a common body of knowledge, the internalization of which enables people to operate as effective members of their society. Through mass media, awareness should be created to both parents and the adolescents in the society. The radio, television, video, and computer programmes should emphasis the importance of sexuality education in secondary schools, and the implications of lack of it. This awareness will go a long way in breaking the cultural barriers that are binding sexuality education both in the families and in the schools.

Grasping what sexuality is all about and how it can be rightly related to our life will go a long way to help avoid much guilt-feeling and life problems. Ochiagha (1994) recommended that the positive aspects of Christian living as well as the spiritual values that should be embedded in it should be built into the handbook of the various religious organizations. If the importance of sexuality education and the implications of lack of it are contained in these handbooks, parents, and youths need no other prophet to come and preach these values to them.

\section{Conclusions and Recommendations}

Counsellor respondents have identified as part of their roles in promoting sexuality education, value re-orientation for students, enlightenment programme for parents on the need for the growing adolescents to be kept abreast of their developmental changes, information dissemination on benefits inherent in sexuality education, and creating awareness through lectures, seminars, workshops, and conferences on the objectives of sexuality education. However, there are some perceived constraining factors indicated by the respondents in carrying out such roles. Such constraining factors are lack of fund and lack of awareness on the side of the public on what sexuality education is all about cultural and religious interferences. All these hinder the promotion of sexuality education in secondary schools. It was equally suggested by the respondents that measures like provision of adequate funds, removal of cultural inhibitions, the use of media and oral instruction 
as well as value re-orientation could be used to eliminate the constraining factors to the promotion of sexuality education in secondary schools.

Policy-makers should find intervention strategies for removal of the perceived constraints as a way of enhancing sexuality education in secondary schools. There is the need to include in the school curriculum sexuality education to prevent the youths from learning about sex secretly from friends. Parents should be enlightened equally on the need to give their children sexuality education early in life so that what the school gives them would not appear immoral/sinful.

\section{References}

Anameze, L. N. (2002). Sex education and marriage counseling with goals, contents and methods. Jos: Fab. Anieh Ltd.. Araniego, J. (2003). Counselling services. Retrieved July 21, 2004, from http://isis.fastmail. usf.edu/counsel/personal.htm Bulus, I. (1990). Guidance practices in schools. Jos: Ehindero Nigeria Ltd..

Federal Republic of Nigeria. (1998). National policy on education (3rd ed.). Lagos: NERDC Press.

Grugni, A. (1996). Sex education. Bombay: St. Pauls, Bandra.

Harold, L. (2002, Nov. 22). CASSON canvasses counseling centres in tertiary institutions. The Punch, 39.

Manderson, L. (1998). Applying medical anthropology in the control of infectious disease. Tropical Medicine and International Health, 3(12), 1020-1025.

Nwabuisi, E. M. (2000). Values and education. Onitsha: Spiritan Publishers.

Ochiagha, C. C. (1994). The future of the Nigeria youths: A counseling perspective. Enugu: Snaap Press Ltd..

Ochiagha, C. C. (1997). Value re-orientation programme for youths: An alternative approach. Enugu: Snaap Press Ltd.

Ochiagha, C. C. (1999). Issues in human sexuality. Onitsha, Nigeria: Spiritan Publishers.

Okumu, A. L. (2001). Women secularism and democracy; women's role in the regeneration of society. A paper presented in The Conference on Sharia at Commonwealth Center, Commonwealth Institute, Kensington, London, April 14-15, 2001.

Okunwa, F. (1999, Oct. 13). Media and sexuality. The Tribune, 2.

Omeje, J. C. (2003). The role of counseling in improving instruction in tertiary institution: A case study of University of Nigeria, Nsukka. The Journal of World Council for Curriculum and Instruction (Nigeria Chapter, WCCI), 4, 83-91. 